\title{
Management of foot burns with an emphasis on high-risk groups
}

Jason Diab, Miranda Pye, Christine Parker, Justine O'Hara, Peter KM Maitz, Andrea C Issler-Fisher

\section{Background}

Burns injuries are dynamic and evolve over time. Burn injuries to the feet present with seasonal variation, affecting clinical outcomes for certain high-risk groups. Although they affect a very small percentage of the body, burn injuries to the feet can affect mobility, morbidity and rehabilitation, particularly in patients with diabetes.

\section{Objective}

The aim of this article is to provide an understanding of seasonal variation in foot burns for high-risk groups and how to manage them appropriately. This article provides a comprehensive analysis on epidemiology, pathology and management, with the aim of providing guidance for general practitioners (GPs).

\section{Discussion}

The management of foot burns is multidisciplinary, involving GPs, allied health specialists, nurses, medical and surgical specialties. The epidemiological variations of these injuries have shown differences in clinical outcomes among high-risk groups such as the elderly and people with diabetes. Education and prevention are crucial in reducing the rate of injury in the rising number of patients in high-risk groups.
GENERAL PRACTITIONERS (GPs) may often be the first involved in managing minor burns. Not all burn injuries require a transfer to a specialist burns centre; therefore, a good understanding of burn care and when to refer is important to reduce the risk of complications. With the increase of diabetes in an ageing society, burn injuries to the feet are a unique and increasing challenge for the modern healthcare system.

The warm Australian climate and outdoor living pose a unique clinical profile for foot burns, with burn injury mechanisms varying across seasons and within patient subgroups. Albeit a very small percentage of total body surface area burnt, foot burns can have significant morbidity, affecting function and mobility. ${ }^{1}$ Medical comorbidities and complications associated with foot burns add cost to care because of increased length of stay and ongoing outpatient treatment. ${ }^{2}$ The International Diabetes Federation estimates 1.1 million Australians aged between 20 and 79 years have diabetes. ${ }^{3}$ The impact of diabetes plays a significant part in the healing process, and the role of the GP is integral to a successful outcome. Timely identification of the burn injury, good diabetes control and optimal wound management can prevent a superficial burn injury from progressing to a deeper injury; in turn, it may also avoid surgical intervention such as grafting or even amputation. The focus of this article is to understand the epidemiological variations of adult foot burns across seasons and how to manage foot burns in the primary care setting.

\section{Clinical epidemiology}

The most common cause of adult foot burn is scalds. ${ }^{4} \mathrm{~A}$ recent retrospective analysis of adult foot burns at Concord Repatriation General Hospital has shown that there are differences in seasonal variations between foot burns affecting patients with and without diabetes. These two groups have shown statistically significant differences in clinical outcomes such as burn depth, wound infections and number of operations, with patients with diabetes having worse outcomes. Foot burns affecting patients without diabetes occur most frequently in summer (27.2\%); foot burns affecting patients with diabetes appear to be more common in winter (33.3\%), with 1.7 times the risk during winter when compared with people without diabetes. ${ }^{5}$ Similarly, the mechanisms of injury (Figure 1) are significantly different between the two groups, with scald (odds ratio [OR]: 0.4) most common for patients without diabetes and contact burns (OR: 3.8) most common for patients with diabetes $(P=0.021)$.

Another high-risk group is the elderly (aged $\geq 65$ years), compounded by 
various comorbidities and mechanisms leading to poor clinical outcomes. A recent retrospective analysis of burns in the elderly showed that lower limb burns occurred most frequently in winter as a result of scalding from hot liquids. Burns often occur at home, with statistically significant differences between activities men and women undertake (men: flame, women: scald), age and season. ${ }^{6}$ Pathophysiological skin changes, poor nutrition and a frequent lack of appropriate first aid in the elderly may lead to burn wound depth progression and further unnecessary complications and procedures, as well as longer hospital stays. ${ }^{7}$

\section{Pathophysiology}

Jackson's model of burn depth describes the burn wound in three zones: zone of coagulation, zone of stasis and zone of hyperaemia. ${ }^{8}$ With diabetes having an impact on a microvascular and macrovascular level, the potential for prolonged exposure to a stimulus without appropriate neurological feedback results in deeper burns (Figure 2). Healing depends on influencing the zone of stasis, with adequate first aid (cool running water for 20 minutes) within three hours post-injury and wound care in the initial phase. ${ }^{9}$

\section{Clinical presentation}

Burn wounds are dynamic. A comprehensive history and examination at the time of injury is key to determining management and providing appropriate referral. Using a systematic approach is fundamental to assessing patients with burn injuries and identifying concomitant injuries

Figure 1. Comparison of mechanism of injury for diabetic and non-diabetic foot burns
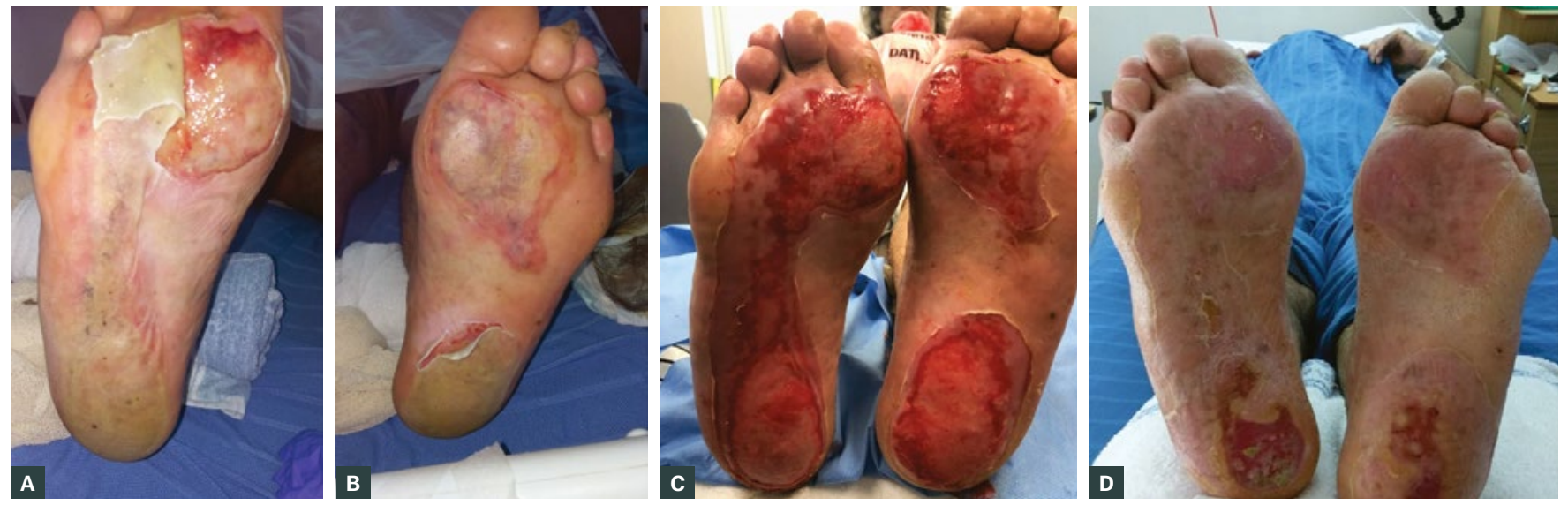

Figure 2. A man aged 67 years with poorly controlled diabetes presented with mid-dermal burns to feet that occurred while walking barefoot on a hot $\left(>40^{\circ} \mathrm{C}\right)$ summer's day.

A. Right foot shows mid-dermal burns with poor capillary response and sensation; B. Left foot shows two distinct areas from walking on 'ball and heel'; c. On presentation, vigorous and careful debridement of non-viable tissues shows a classic pattern from walking with features of mid-dermal and full-thickness burns; the area had poor capillary response and the feet were insensate; $\mathbf{D}$. After eight weeks of debridement and dressings, healing gradually takes place. 
and comorbidities. A focused history should include: date and time of injury, mechanism of injury, first aid provided, Adsorbed Diphtheria and Tetanus (ADT Booster) status, allergies, regular medications and general medical history.

Examination of a foot burn injury involves:

1. examination of the wound for location; size; depth; necrosis; exposed bone, joint or tendon; oedema; exudate; signs of infection; and sensation (pain)

2. the diagnosis of burn depth as per the Australian and New Zealand Burns Association's burn depth chart (http:// anzba.org.au/assets/ANZBA-InitialManagement-of-Small-Burns.pdf $)^{10}$

3. dermatological assessment of feet (skin changes, sweating, nails, ulceration, blistering, deformity, muscle wasting) ${ }^{11}$

4. musculoskeletal assessment of feet, including deformities and gait

5. vascular examination of the lower limb, including assessment of pulses, signs of peripheral arterial disease and venous insufficiencies

6. assessment of peripheral neuropathy

7. general cardiovascular examination and assessment of diabetic control (blood glucose level and/or glycated haemoglobin [HbA1c]).

\section{Diagnosis and investigations}

Burn injuries to the feet are multifactorial, and a comprehensive system-based point assessment is required to guide individualised patient-centred care. Changes in circulation and nerve function must be identified early to allow for appropriate interventions to be undertaken and to ensure optimal outcomes. Particularly in people with diabetes and immunocompromised patients, it is important to be aware of possible progression to necrotising fasciitis or osteomyelitis, which can be masked by the burn injury and have life-threatening consequences. Non-specific signs similar to soft tissue infections that evolve rapidly may also be present, such as features of necrotising fasciitis. ${ }^{12}$ Therefore, correct identification of the foot burn and immediate referral to the local burns unit is essential. If the patient is managed as an outpatient, biochemical investigations (eg full blood examination, urea and electrolytes, C-reactive protein, comprehensive metabolic panel, liver function tests, fasting glucose, $\mathrm{HbAlc}$, fasting lipids), ${ }^{13}$ wound swabs or X-ray imaging should be considered initially for baseline measurements.

\section{Management}

Optimal burn wound management involves: cleansing, removal of non-viable tissue, infection and inflammation control, moisture balancing, pain management, minimising bacterial colonisation, reducing inflammation, promoting re-epithelisation, and meticulous pressure management with pressure offloading of burn area to assist in healing. The aim is to restore functional capacity in the feet by reducing oedema and pain so mobility ensues. ${ }^{14}$ Multidisciplinary management focuses on the model of holistic care that addresses the medical comorbidities, the burn injury and functional return to living. All patients with diabetes who experience foot burns require optimisation of glycaemic control and, if further input is necessary, endocrinology referral. Frequently, burns to feet require long-term investment, often months, in management and dressings to achieve healing. Telehealth support is available from burns units through videoconference, teleconference or email - depending on local protocols - to provide specialised support to patients and clinicians in rural and remote areas.

\section{Wound care}

There is a plethora of dressings available for different wounds. Primary dressing selection is guided by addressing wound features in order of priority (Table 1). ${ }^{15}$ The aim of dressings is to promote wound healing by: managing exudate, optimising moisture balance, protecting the wound, avoiding wound trauma, providing antimicrobial coverage, reducing inflammation and debriding non-viable tissue. An important aspect of foot burn dressing is to ensure that the web spaces between the toes are separated to allow for dressing contact. This aims to prevent wound webbing and contractures on wound healing, as well as maceration and ulceration of healthy skin. To improve wound healing, physiotherapists or podiatrists often aim to offload pressure on the affected area and elevate the feet to manage oedema, improve circulation and prevent pressure areas. ${ }^{16}$ Wound closure is not the end of the patient's burn journey. Physiotherapists and occupational therapists are actively involved in rehabilitation for mobility, scar management and return to work. Once the wounds are fully closed and stable, the patient should be encouraged to ambulate as normally as possible, without the use of aids, to ensure they retain full range of movement and function.

\section{Prevention and education}

Burn prevention, education on first aid, knowledge of seasonal variations of common burn mechanisms (Figure 3) and awareness of the dangers of peripheral neuropathy can all be considered as part of the GP armamentarium for preventing burn injuries. The lack of sensation in peripheral neuropathy can lead to significant burn injury, and it is important to educate patients and raise awareness, particularly during the peak seasons of summer and winter, with referral to podiatry services. The annual healthcare costs of people with diabetes who have both microvascular and macrovascular complications range from $\$ 3468$ to $\$ 16,698 .{ }^{17}$ It is well documented that people with diabetes have increased lengths of hospital stay ${ }^{18}$ and intensive care admissions, and a high incidence of renal failure. ${ }^{19}$

\section{Box 1. Foot burn prevention advice for patients with diabetes}

\footnotetext{
- Always check shower and bath water temperature.

- Avoid sitting too close to campfires, fireplaces and heaters.

- Wear foot protection, especially when outdoors and when near hot food or drinks.

- Regularly check feet for any wounds or changes.
} 


\section{Table 1. Primary dressing for foot burns}

\begin{tabular}{|c|c|c|c|c|c|}
\hline & Paraffin gauze & Silver & Silicone & Hydrofibers & Hydrocolloids \\
\hline Properties & $\begin{array}{l}\text { - Medicated and } \\
\text { non-medicated } \\
\text { - Open mesh } \\
\text { - Cotton } \\
\text { - Rayon } \\
\text { - Gauze }\end{array}$ & $\begin{array}{l}\text { - Nanocrystalline silver } \\
\text { coated mesh with } \\
\text { inner rayon layer } \\
\text { - Hydrofibers } \\
\text { - Silicone foams }\end{array}$ & $\begin{array}{l}\text { - Polymers } \\
\text { - Adhesive } \\
\text { - With or without } \\
\text { foam }\end{array}$ & $\begin{array}{l}\text { - Carboxymethylcellulose } \\
\text { - Woven or non-woven } \\
\text { gelling fiber } \\
\text { - Can contain silver }\end{array}$ & $\begin{array}{l}\text { - Gelatin, pectin or } \\
\text { carboxymethylcellulose } \\
\text { - Can be: } \\
\text { - adhesive } \\
\text { - occlusive } \\
\text { - contain foam } \\
\text { - come in paste form }\end{array}$ \\
\hline Rationale & $\begin{array}{l}\text { - Non-adherent } \\
\text { - Can contain } \\
\text { antiseptic }\end{array}$ & $\begin{array}{l}\text { - Broad spectrum } \\
\text { antimicrobial } \\
\text { - Anti-inflammatory }\end{array}$ & $\begin{array}{l}\text { - Easy to apply } \\
\text { - Atraumatic } \\
\text { - Decrease pain on } \\
\text { removal } \\
\text { - Protection }\end{array}$ & $\begin{array}{l}\text { - Cellulose turns to gel } \\
\text { - Absorb exudate vertically } \\
\text { - Debride slough and } \\
\text { necrotic tissue } \\
\text { - Reduce periwound } \\
\text { maceration } \\
\text { - Conformable }\end{array}$ & $\begin{array}{l}\text { - Encourage autolysis of } \\
\text { necrotic tissue } \\
\text { - Can absorb exudate } \\
\text { - Can be waterproof }\end{array}$ \\
\hline Indication & $\begin{array}{l}\text { - Dermal burns } \\
\text { - Low-to-moderate } \\
\text { exudate } \\
\text { - If signs of infection, } \\
\text { use product } \\
\text { impregnated with } \\
\text { antiseptic }\end{array}$ & $\begin{array}{l}\text { - Dermal to full- } \\
\text { thickness burns } \\
\text { - Infected/colonised } \\
\text { wounds } \\
\text { - Erythema } \\
\text { - Inflammation } \\
\text { - Reduce risk of } \\
\text { infection }\end{array}$ & $\begin{array}{l}\text { - Superficial to } \\
\text { mid-dermal burns } \\
\text { - Low-to-moderate } \\
\text { exudate } \\
\text { - Infected wounds } \\
\text { (silver dressings, Ag) } \\
\text { - Skin trauma } \\
\text { - Reduce pain } \\
\text { - Pressure area } \\
\text { prophylaxis }\end{array}$ & $\begin{array}{l}\text { - Dermal burns } \\
\text { - Infected wounds (AG) } \\
\text { - Moderate-to-heavy } \\
\text { exudate } \\
\text { - Debride }\end{array}$ & $\begin{array}{l}\text { - Dermal to full-thickness } \\
\text { burns } \\
\text { - Low-to-high exudate } \\
\text { - Pressure injuries } \\
\text { - Donor sites }\end{array}$ \\
\hline Precautions & $\begin{array}{l}\text { - Foreign body } \\
\text { reaction } \\
\text { - Sensitivities } \\
\text { to medication } \\
\text { (eg chlorhexidine) }\end{array}$ & $\begin{array}{l}\text { - Long-term use } \\
\text { - Sensitivity } \\
\text { - Non-infected or } \\
\text { non-inflamed wounds } \\
\text { - Use with saline, zinc } \\
\text { or antimicrobials } \\
\text { - May mask infection }\end{array}$ & $\begin{array}{l}\text { - Sensitivity } \\
\text { - Maceration if used } \\
\text { with creams }\end{array}$ & $\begin{array}{l}\text { - Dry wounds } \\
\text { - Hard necrotic tissue } \\
\text { - Bleeding wounds }\end{array}$ & $\begin{array}{l}\text { - Fragile skin } \\
\text { - Bleeding } \\
\text { - Infection }\end{array}$ \\
\hline Application & $\begin{array}{l}\text { - Change every } \\
\text { 1-2 days }\end{array}$ & $\begin{array}{l}\text { - Leave intact for three } \\
\text { days (some types for } \\
\text { seven days) } \\
\text { - Total 2-3 weeks or } \\
\text { resistance may occur }\end{array}$ & $\begin{array}{l}\text { - Leave intact for } \\
\text { 5-7 days }\end{array}$ & $\begin{array}{l}\text { - Allow for } 2-5 \mathrm{~cm} \text { margin } \\
\text { - Change if highly exuding } \\
\text { - Cease when dry (eg low- } \\
\text { to-nil exudate) }\end{array}$ & $\begin{array}{l}\text { - Change every } 2-7 \text { days } \\
\text { - Change if leaking } \\
\text { - Change if } 70 \% \text { full of } \\
\text { exudate } \\
\text { - Allow for } 2.5 \mathrm{~cm} \\
\text { margin }\end{array}$ \\
\hline
\end{tabular}

Patient education on good foot care, burn prevention advice (Box 1), optimisation of glycaemic control and improvement of risk factors for poor wound healing (eg smoking, nutritional deficiencies and cardiovascular comorbidities) by GPs are essential components for successful long-term outcomes of wound management. ${ }^{20}$ Multidisciplinary management of foot burns affecting patients with diabetes with open loop communication and clear goals between GPs, allied health specialists, podiatrists and burns units can facilitate best patient outcomes.

\section{Long-term goals}

Long-term goals in practice should focus on optimising glycaemic control, optimising pain management using multimodal therapy, addressing microvascular disease and providing opportunistic season-focused education for high-risk groups on patient activities and understanding of burns. With the rise of non-communicable disease, the expected number of patients with diabetes presenting to burn units will increase, with a shift towards holistic care to prevent post-burn diabetic disease-related admissions and other chronic diseases. ${ }^{21,22}$

\section{When to refer}

All foot burns should be referred. ${ }^{23}$ If there is uncertainty about diagnosis or management for a particular foot burn, discussion with a local burns unit is encouraged. If the 
clinical presentation is not consistent with the typical description of foot burns, prompt referral and thorough documentation is recommended. If the patient has diabetes or is elderly, prompt referral and workup should be made simultaneously.

\section{Key points}

- GPs often are the first professionals contacted for foot burns. A thorough burn history, general examination and focused wound assessment are essential.

- Foot burns should be discussed with and referred early to a burns unit for multidisciplinary investigation and management.

- There are seasonal variations in presentations and clinical outcomes patients with foot burns.

- Timely referral is particularly important for high-risk groups, who should have season-based burn prevention education on common burn mechanisms.

\section{Authors}

Jason Diab MBBS, BMedSci, MIPH, MS, Surgical registrar, Burns Unit, Concord Repatriation General of patients with diabetes and elderly

Hospital, NSW; Clinical Associate Lecturer, Concord Clinical School, University of Sydney, NSW; Clinical Associate Lecturer, School of Medicine, University of Notre Dame, Sydney, NSW

Miranda Pye BN, Grad Dip (Nursing Science - Burns Nursing), MN (NP), Clinical Nurse Specialist, Burns Unit, Concord Repatriation General Hospital, NSW

Christine Parker BN, Nurse Unit Manager, Burns Unit, Concord Repatriation General Hospital, NSW

Justine O'Hara BSc, MBBS (Hons), FRACS,

Burns and Plastic Surgeon, Burns Unit, Concord Repatriation General Hospital, NSW

Peter KM Maitz AM, MD, FRACS, Director, Burns Unit, Concord Repatriation General Hospital, NSW; Professor of Burns, ANZAC Research Institute,

Concord Repatriation General Hospital, NSW

Professor of Burns, Concord Clinical School, University of Sydney, NSW

Andrea C Issler-Fisher MD, PhD, EBOPRAS, Burns Fellow, Burns Unit, Concord Repatriation General Hospital, NSW; Clinical Lecturer, ANZAC Research Institute, Concord Repatriation General Hospital, NSW; Clinical Lecturer, Concord Clinical School, University of Sydney, NSW

Competing interests: None.

Funding: None.

Provenance and peer review: Not commissioned, externally peer reviewed.

Correspondence to:

jdmisciali@gmail.com

\section{Acknowledgements}

The authors would like to extend their acknowledgement to the team members at the Concord Burns unit, who provided ongoing support They wish to thank Anne Darton and the New South Wales Agency for Clinical Innovation Statewide Burn Injury Service Data Registry for their assistance with data acquisition.

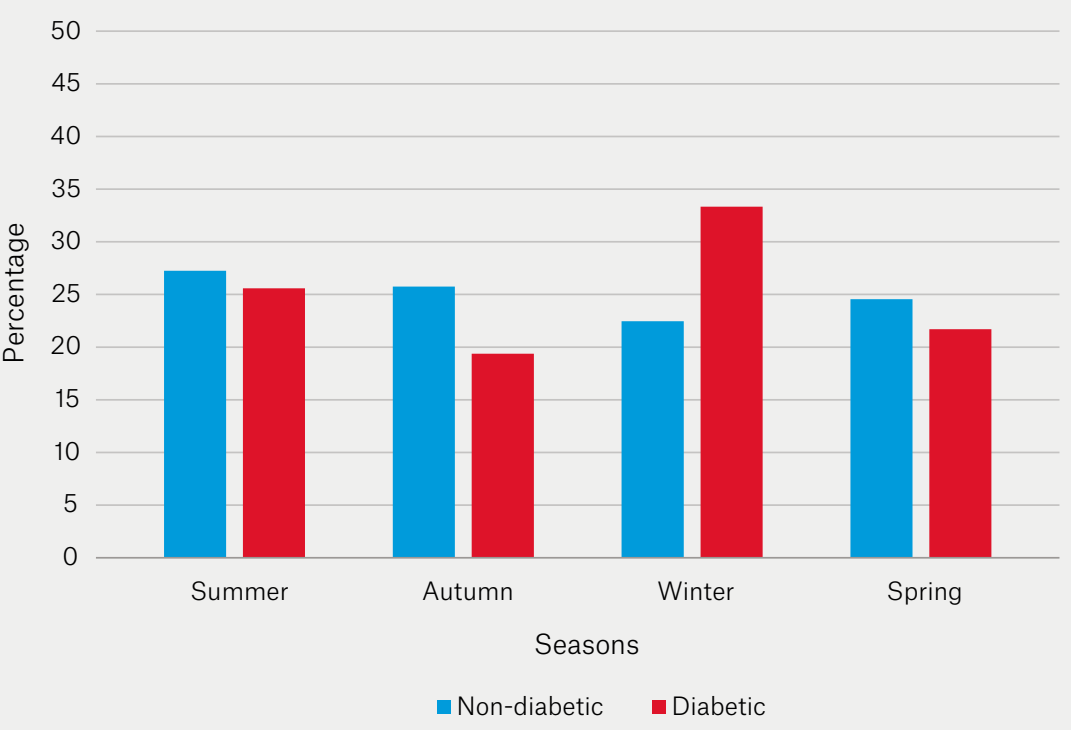

Figure 3. Seasonal variations of foot burns among diabetic and non-diabetic populations

\section{References}

1. Memmel H, Kowal-Vern A, Latenser BA. Infections in DM burn patients. Diabetes Care 2004;27:229-33.

2. Duke JM, Randall SM, Fear MW, et al. Increased admissions for diabetes mellitus after burn. Burns 2016:42(8):1734-39. doi: 10.1016/j. burns.2016.06.005.

3. International Diabetes Federation. IDF Diabetes Atlas, 8th edition. Brussels, BE: IDF, 2017. Available at www.diabetesatlas.org/en/resources [Accessed 2 March 2021].

4. Hemington-Gorse S, Pellard S, Wilson-Jones N, Potokar T. Foot burns: Epidemiology and management. Burns 2007;33:1041-45. doi: 10.1016/j.burns.2006.11.014.

5. Diab J, O'Hara J, Pye M, Parker C, Maitz PKM, Issler-Fisher A. Foot burns: A comparative analysis of diabetic and non-diabetic patients. Burns 2020;5:S0305-4179(20)30483-6. doi: 10.1016/j. burns.2020.07.024.

6. Diab J, Lebler R, Issler-Fisher A et al. Clinical epidemiological analysis of burns in the elderly. Available at www.anzbaasm.com/4992 [Accessed 3 March 2021]

7. Ho WS, Ying SY, Chan HH. A study of burn injuries in the elderly in a regional burn centre. Burns 2001;27(4):382-85. doi: 10.1016/s03054179(00)00146-7.

8. Jackson DM. The diagnosis of the depth of burning. Br J Surg 1953;40(164):588-96. doi: 10.1002/bjs.18004016413.

9. Cuttle L, Kempf M, Liu PY, Kravchuk O, Kimble RM. The optimal duration and delay of first aid treatment for deep partial thickness burn injuries. Burns 2010;36(5):673-79. doi: 10.1016/j. burns.2009.08.002.

10. Australian and New Zealand Burns Association. Initial management of small burns. Albany Creek, Qld: ANZBA, 2014. Available at http://anzba.org. au/assets/ANZBA-Initial-Management-of-SmallBurns.pdf [Accessed 2 March 2021].

11. Boulton AJ, Armstrong DG, Albert SF, et al. Comprehensive foot examination and risk assessment: A report of the task force of the Foot Care Interest Group of the American Diabetes Association, with endorsement by the American Association of Clinical Endocrinologists. Diabetes Care 2008;31(8):1679-85. doi: 10.2337/dc08-9021.

12. Diab J, Bannan A, Pollitt T. Necrotising fasciitis. BMJ 2020;369. doi: 10.1136/bmj.m1428.

13. Clark A, Neyra JA, Madni T, et al. Acute kidney injury after burn. Burns 2017;43(5):898-908. doi: 10.1016/j.burns.2017.01.023.

14. National Pressure Ulcer Advisory Panel, European Pressure Ulcer Advisory Panel and Pan Pacific Pressure Injury Alliance. Prevention and treatment of pressure ulcers: Clinical practice guideline. Osborne Park, WA: Cambridge Media, 2014.

15. NSW Agency for Clinical Innovation. Minor burn management: Clinical guidelines. 4th edn. Chatswood, NSW: ACl, 2019.

16. NSW Agency for Clinical Innovation. Statewide Burn Injury Service. Burn physiotherapy and occupational health guidelines. Chatswood, NSW: $\mathrm{ACl}, 2017$. Available at www.aci.health.nsw.gov. au/ data/assets/pdf file/0018/236151/BurnsPT-ŌT-Guidelines.pdf [Accessed 2 March 2021].

17. Baker IDI Heart and Diabetes Institute. Diabetes: The silent pandemic and its impact on Australia. Melbourne, Vic: Baker IDI Heart and Diabetes Institute, 2012. Available at https:// static.diabetesaustralia.com.au/s/fileassets/ diabetes-australia/e7282521-472b-4313-b18ebe84c3d5d907.pdf [Accessed 2 March 2021]. 
18. Barsun A, Sen S, Palmieri TL, Greenhalgh DG. A ten-year review of lower extremity burns in diabetics: Small burns that lead to majo problems. J Burn Care Res 2013; 34(2):255-60. doi: 10.1097/BCR.0b013e318257d85b.

19. Kimball Z, Patil S, Mansour H, Marano MA Petrone SJ, Chamberlain RS. Clinical outcomes of isolated lower extremity or foot burns in diabetic versus non-diabetic patients: A 10-year retrospective analysis. Burns 2013;39(2):279-84. doi: 10.1016/j.burns.2012.06.006.

20. Murphy CV, Coffey R, Cook CH, Gerlach AT, Miller SF. Early glycemic control in critically

ill patients with burn injury. J Burn Care Res 2011;32(6):583-90. doi: 10.1097/ BCR.0b013e31822dc3da.

21. Goutos I, Nicholas RS, Pandya AA, Ghosh SJ. Diabetes mellitus and burns. Part I: Basic science and implications for management. Int J Burns Trauma 2015;5(1):1-12.

22. Goutos I, Nicholas RS, Pandya AA, Ghosh SJ. Diabetes mellitus and burns. Part II: Outcomes from burn injuries and future directions. Int $J$ Burns Trauma 2015;5(1):13-21.

23. Australian and New Zealand Burns Association. ANZBA referral criteria. Albany Creek, Qld: ANZBA, 2019. Available at https://anzba.org.au/ care/referral-criteria [Accessed 2 March 2021]. 